\title{
O Giacometti de Genet
}

\section{Paula Glenadel}

Tratarei, neste texto, não exatamente da obra de Giacometti, mas da leitura que dela faz Jean Genet (em $O$ ateliê de Giacometti), escritor com cuja obra venho convivendo há algum tempo, sempre intrigada com o seu enorme potencial de estetização de algo que o termo miséria poderia abranger. Discutirei, portanto, nesse agenciamento Genet-Giacometti, alguns valores que tal estetização pode assumir, trazendo para minha leitura trechos de Diário de um ladrão em que a exploração do submundo dos ladrões, mendigos, homossexuais, prostitutos e presidiários se faz mais presente. Caberia indagar-se em quais sentidos do termo "exploração" é possível pensar aqui, pois há sempre o risco de que a aventura no território do outro abra lugar à apropriação devoradora da miséria alheia, e até mesmo da própria.

\section{Estetizar}

Parto de um comentário de Genet sobre Giacometti:

A beleza tem apenas uma origem: a ferida, singular, diferente para cada um, oculta ou visível, que o indivíduo preserva e para onde se retira quando quer deixar o mundo para uma solidão temporária, porém profunda. Há, portanto, uma diferença imensa entre essa arte e o que chamamos o miserabilismo. A arte de Giacometti parece querer descobrir essa ferida secreta de todo ser e mesmo de todas as coisas, para que ela os ilumine."

Moduladas diferentemente, adotando acentos específicos aqui e ali, essas palavras de Genet resumem o sentido de sua crítica sobre Giacometti. Para se atingir esse lugar da solidão absoluta e mais íntima de cada ser - e cada coisa - o trabalho da arte, a estetização que ela praticará em relação ao objeto que tomar por modelo, motivo ou pretexto, deve ser o de um desnudamento. O texto de Genet sobre Giacometti abunda em expressões próximas desse desnudamento: "desnudando-se o bastante para descobrir esse lugar secreto”, "desfazer essa aparência”, "quando as máscaras forem retiradas", "despojar o objeto", "na mais ingênua nudez"*
" (Genet, Jean. O ateliê de Giacometti. São Paulo: Cosac \& Naify Edições, 2000: 12.13) 
" (Cf. Derrida, Jacques. Glas. Paris: Galilée, 1974)

" (Genet, Jean. O ateliê de Giacometti. Op. cit.: 21)

* (: 40) * (: 72)

*(: 38)

" (Genet, Jean. Journal du voleur. Paris: Gallimard, 1949: 28)

* (: 29)

(: 29)
Mas o que está "por debaixo", "atrás", "além”, da aparência do mundo visível, que Genet tenta num primeiro momento opor ao segredo mais precioso do ser? Para ele, cuja obra já foi descrita como uma espécie de "enroscamento" em torno de um centro vazio, associada aos temas do luto e do desejo*, é provável que não se trate de um conteúdo pleno, nem de uma verdade no sentido "matemático" do termo, e talvez nem mesmo de uma "moral", por mais perversa que ela fosse. O que subjaz ao visível é a solidão, ou seja, um certo sentimento do isolamento, do vazio de tudo. E, no contexto da crítica de Genet, essa solidão é sentida não como miséria, mas como "glória", "realeza secreta", "majestade nua", "preciosa"*.

Se quisermos empregar aqui uma categoria oriunda da filosofia política, o que se justificaria pela reflexão sobre o tema da miséria, tal estado de solidão absoluta e de vazio é o mais democrático possível, pois ele representa "esse ponto precioso em que o ser humano seria devolvido ao que tem de mais irredutível: a solidão de ser exatamente igual a qualquer outro"*. A arte de Giacometti, que funciona para Genet como paradigma do trabalho da arte, de seu potencial libertador levado ao máximo, atinge esse patamar através da exaltação de seres e objetos que toma dentre uma massa informe de coisas desvalorizadas ou menosprezadas.

Em Diário de um ladrão, Genet pratica essa exaltação de modo intensivo. Cito apenas alguns momentos desse tipo de operação:

Tornados tão úteis para o conhecimento de nosso apequenamento quanto as jóias para o conhecimento do que se chama de triunfo, os piolhos eram preciosos. Tínhamos ao mesmo tempo vergonha e glória deles*.

Num erotismo solitário a lepra se consola e canta seu mal. A miséria nos erigia. Através da Espanha, desfilávamos uma magnificência secreta, velada, sem arrogância*.

Ao detido a prisão oferece o mesmo sentimento de segurança que um palácio real ao convidado de um rei*.

"Arte" aqui é um processo de reapropriação do mundo, de reinterpretação dos dados do "dado", do "vivido", um processo de revaloração, que permite a tomada de posição e o redimensionamento do sujeito em face daquilo de que não se escapa, a realidade, a linguagem tomada como doxa, a violência, a exclu- 
são, a solidão, entre outros estados paroxísticos ou medíocres da miséria. A arte moderna vem trabalhando de modo drástico a clivagem entre a realidade e a arte. Assim, desde Baudelaire, pelo menos, tem sido possível trabalhar dissociando o belo do verdadeiro e do bom. Essa autonomia da arte representa provavelmente uma conquista no sentido conceitual da estética, mas é logo captada por jogos do "mercado”, pois o que há de mais "real” ou "verdadeiro", ou ainda "excelente" num certo sentido, do que o valor comercial de um objeto, fosse ele o mais radical dos objetos artísticos, o mais contestador da ordem mental ou social estabelecida?

A análise de Genet não se prende a esse aspecto da arte, ele fala dentro de um universo tido como homogêneo, o das significações, da força, da beleza da obra de arte. No interior desse universo, a prática de Giacometti acaba por revelar a solidão de todos a partir da solidão dos mais evidentemente sós. A beleza da obra é o efeito de uma espécie de simbiose entre a solidão do artista e a solidão do ser ou da coisa estetizados. Há, contudo, diferentes modalidades de interação ou de identificação, ou ainda de apropriação, dependendo de como se queira designar o processo de estetização. Digo "simbiose", embora pudesse também estar empregando o termo "parasitismo". Caberia discutir até que ponto a "intenção" de um artista é o que determina o tipo de estetização.

Nesse sentido, interessantes são os casos trazidos por Genet para ilustrar a arte de Giacometti. Trata-se das putas dos bordéis cujo desaparecimento Giacometti lamenta, do mendigo árabe cego encontrado num café, da mendiga amiga de Giacometti, do velho do trem enfim - o único que transcreverei aqui, pelo teor da reflexão sobre a questão de uma espécie de "caridade" fundamental que propicia. É Genet quem conta:

Há cerca de quatro anos, eu estava no trem. Diante de mim, no compartimento, estava sentado um velhinho horroroso. Sujo e manifestamente mau, algumas de suas reflexões o provaram. Recusando prosseguir uma conversa desagradável, tentei ler, mas involuntariamente olhava para aquele velhinho: ele era muito feio. Seu olhar, como se diz, cruzou com o meu e, se foi breve ou demorado, já não sei, mas conheci de súbito a dolorosa - sim, a dolorosa sensação de que qualquer homem 'valia' exatamente - desculpem, mas é 'exatamente' [o] que eu quero ressaltar - o mesmo que qualquer outro. 'Qualquer um', pensei, 'pode ser amado apesar de sua feiúra, imbecilidade e malvadez’”.

" (Genet, Jean. 0 ateliê de Giacometti. Op. cit.: 37) 
O próprio Giacometti também é apresentado como um "pobre”, ou alguém que tivesse feito essa “opção", se é que isso corresponde a uma: sujo, ocupando um ateliê caindo aos pedaços, com grande simpatia pela poeira e pelos objetos velhos, feliz ao saber que mancaria após uma operação. Caberia nessa altura indagar o que é de quem aqui. A persona do artista acrescenta-se à sua obra ou à performance do crítico, ou seja, a simpatia de Genet pelos marginais e desamparados condiciona seu entendimento de Giacometti, bem como a simpatia de Giacometti pelos miseráveis informa sua obra, embora não os tome diretamente por "modelos".

Já sabemos, portanto, algo - ou não sabemos quase nada sobre o que é estetizado por Giacometti. Mas o que significa aqui estetizar? A série de termos relativos à estética vem do verbo grego que quer dizer sentir. Faz-se ouvir aqui, se quisermos prestar atenção em etimologias, gosto talvez duvidoso mas comandado por uma espécie de paixão filológica que talvez me interesse assumir, faz-se ouvir uma faculdade sensível, uma sensibilidade, que indica que o trabalho da arte procede por afetos. Uma importante questão para os afetos reside na oscilação entre proximidade e distância - justamente o aspecto que é levantado por Genet como um critério de valor para a apreciação da arte de Giacometti. Sobre certas estátuas dele, Genet diz:

Também provocam em mim um curioso sentimento: são familiares, caminham na rua. Porém, estão no fundo dos tempos, na origem de tudo, aproximam-se e recuam sem cessar, numa imobilidade soberana. Se meu olhar tenta amansá-las, aproximar-se delas - mas sem furor, sem cólera nem ira, simplesmente por causa de uma distância entre mim e elas que eu não tinha notado, distância tão comprimida e reduzida a ponto de eu acreditá-las muito próximas -, afastam-se a perder de vista: é que essa distância súbito se desdobra*.

Qual seria a posição de Giacometti - produtor da obra - em relação a esse agenciamento entre proximidade e distância comentado por Genet - receptor da obra? Transcrevo um trecho que abre um diálogo entre os dois:

O cachorro em bronze de Giacometti é admirável. Era ainda mais bonito quando sua estranha matéria, gesso misturado com barbante ou estopa, desfiava.[...]

Como eu me espante que haja um animal - é o único entre suas figuras:

ELE: Sou eu. Um dia me vi na rua assim. Um cão*. 
É ele, sou eu: a sensibilidade estética comanda aqui uma identificação com o outro radical representado por um animal, extrapolando o antropomorfismo, embora jogue com uma carga simbólica que é sempre já uma apropriação da alteridade do outro. A aproximação entre o animal e o excluído está em Heidegger, por exemplo, para quem o animal é "pobre em mundo" ${ }^{1}$. Muito distante, muito próximo, estão a arte regeneradora, doadora de dignidade, e os pobres, a miséria sendo "magnificada" pela estetização.

\section{Transfigurar}

Tal estetização é uma transfiguração, uma ilusão que será tanto mais bem-sucedida quanto mais se acreditar nela, segundo sua própria lógica, sem medi-la pela lógica do "real". Acreditar radicalmente nela enquanto jogo, ficção lúdica, implicaria desvalorizá-la em algum outro lugar? Talvez, sobretudo quando se aborda uma questão complexa como a estetização da miséria real. Mas acreditar nessa ficção como "realidade" é algo que se inscreveria numa série naïve ou psicótica, e fingir compará-la com o real para desvalorizá-la é um gesto que remete à viciosa crítica platônica da poesia.

$\mathrm{E}$ de onde sai, aqui em meu texto, a palavra transfiguração $0^{2}$ ? Falo de transfigurar pois se trata da passagem (trans) de uma

${ }^{1}$ Cf. Lettre sur l'humanisme: "Si plantes et animaux sont privés de langage, c'est parce qu'ils sont emprisonnés chacun dans leur univers environnant, sans être jamais librement situés dans l'éclaircie de l'Être. Or seule cette éclaircie est monde. Mais s'ils sont suspendus sans monde dans leur univers environnant, ce n'est pas parce que le langage leur est refusé" (Heidegger, 1976: 94).

${ }^{2}$ Do Littré: TRANSFIGURER (tran-sfi-gu-ré), v. a.

$1^{\circ}$ Changer la figure, le caractère. La légende transfigure les personnages historiques.

L'Académie n'a pas transfigurer à l'actif.

$2^{\circ}$ Se transfigurer, v. réfl. Prendre une autre figure. Il est difficile... que l'ange de ténèbres ne se transfigure quelquefois en ange de lumière, MASS. Carême, Injust. du Monde.

REMARQUE: Transfigurer se dit pour exprimer que la figure prend quelque chose de supérieur et de plus éclatant; cependant on le trouve quelquefois avec le sens de transformer: Qu'il [Needham $]$ s'en tienne à ses anguilles.... que surtout l'envie de se transfigurer en serpent ne lui prenne plus; qu'il ne pense pas qu'il soit en droit de siffler, parce qu'on le siffle, VOLT. Quest. Miracl. e.

HISTORIQUE:

XIIIe s. Vers Medusa riens ne duroit; Car en roche transfiguroit, Tant faisoit felonesses uevres, la Rose, 21018. Et se transfigura en la figure Bretel [nom propre], MERLIN, $\mathrm{f}^{\circ}$ 63, recto. 
figura em outra, com a noção de torná-la "superior" e mais "brilhante”. É também um termo ligado a um contexto religiosomais propriamente católico, porque profundamente instruído por um olhar plástico. $\mathrm{O}$ final do texto do Ateliê não deixa de ecoar estranhamente certos aspectos da religiosidade cristã em sua vertente católica, que caberia talvez repertoriar e interpretar, tarefa que deixo em aberto por enquanto, indicando apenas que a questão passa pelas categorias da humildade e da inocência.

Sob o pretexto de enobrecer - ou aviltar, segundo a moda atual ele (Giacometti) recusa depositar sobre o objeto a mínima aparência - mesmo que delicada, cruel ou tensa - humana.

Diante de um lustre, diz: "É um lustre, é Ele". E nada mais.

E essa súbita constatação ilumina o pintor. O lustre. No papel ele existirá, na mais ingênua nudez.

Que respeito pelos objetos. Cada um tem sua própria beleza porque é “único", nele há o insubstituível.

A arte de Giacometti não é, portanto, uma arte social por ele estabelecer entre os objetos um laço social - o homem e suas secreções - será antes uma arte de mendigos superiores, a tal ponto puros que apenas o reconhecimento da solidão de cada ser e cada objeto os uniria. "Estou só", parece nos dizer o objeto, "capturado numa necessidade contra a qual você nada pode. Se sou apenas o que sou, sou indestrutível. Sendo o que sou e sem reservas, minha solidão conhece a sua"*.

Mas como transfigurar despindo? Não haveria aqui alguma contradição, alguma contrariedade? Não é primeiramente como "disfarce", "véu" "fantasia", que se concebe a ilusão, a aparência? De certo modo, tanto faz, pois despir de uma certa maneira equivaleria, no universo de Genet, a revelar a glória que a vesti-

XIVe s. Uns angles [un ange] laiens se monstra, En la fourme dou roi s'est mis Et de viaire et de figure, Et le mousart roi transfigure [métamorphose], J. DE CONDÉ, p. 150.

XVe s. Mais est abesté le bonhomme, et paist l'herbe, et est transfiguré sans enchantement, Les 15 joyes de mariage, p. 116, dans LACURNE.

XVIe s. Nostre redempteur transfigura nos corps mesprisez en la gloire du sien, CALV. Instit. 802. Voila comment Satan se transfigure en ange de lumiere, ID. Ibid.: 994.

ÉTYMOLOGIE: Provenç. transfigurar, transfigurar; espagn. transfigurar; ital. trasfigurare; du latin transfigurare, de trans, et figurare, figurer.

SUPPLÉMENT AU DICTIONNAIRE:

TRANSFIGURER. - HIST. Ajoutez: XIIe s. Circes, icele qui tant sot, Qui les homes transfigurot, BENOIT DE SAINTE-MORE, Roman de Troie, V. 29775. 
menta busca recriar. Do mesmo modo Giacometti, ao ver as putas vestidas na rua, fica indiferente, mas se as vir num quarto nuas, as vê como deusas. A vestimenta ideal é feita à imagem da nudez gloriosa. Em Diário de um ladrão, a primeira frase é: "A vestimenta dos condenados é listrada de rosa e branco"*, o que dará a Genet a ocasião de compará-los a flores. Por outro lado, nesse livro, há um trecho intrigante, colocando um limite para a estetização, ao falar da nudez, justamente, que aqui funciona mais propriamente como recusa do qualificativo, logo, como recusa da estetização, ponto-limite da linguagem:

Embelezando o que vocês desprezam, eis que meu espírito, cansado desse jogo que consiste em nomear com um nome prestigioso o que faz revirar meu coração, recusa qualquer qualificativo. Os seres e as coisas, sem confundi-las, ele aceita-os todos em sua igual nudez. Depois ele recusa-se a vesti-los. Por isso não quero mais escrever, morro ao pé da Letra*.

Talvez toquemos aqui a diferença entre as artes, pois a plasticidade do procedimento de Giacometti lhe permite trabalhar com a nudez sem que isso seja sinônimo de esgotamento do material ou da linguagem de que dispõe.

O termo transfigurar transita por um contexto religioso, talvez por isso tenha me parecido o mais adequado para caracterizar a dinâmica da arte de Giacometti-lido-por-Genet. Em ambos há paradigmas de estetização da miséria que não se confundem com a "generosidade" ou a "bondade" de ressaltar e acolher essa ferida da solidão de todos - é uma questão de “reconhecimento”, de amor, como ele diz*. A questão do dom ${ }^{3}$ poderia ser aqui invocada, pois tal amor incondicional independe do valor ou do mérito do ser amado. Não se trata de

${ }^{3}$ Cf. Jacques Derrida, Donner le temps 1. La fausse monnaie. (Paris: Galilée, 1991). Nesse texto, a pujança do poema em prosa de Baudelaire (A moeda falsa) e de alguns versos de Mallarmé permite a Derrida aglutinar várias reflexões importantes sobre as questões do dom, da pobreza, da justiça e da escrita como crédito, portanto como mecanismo que se inscreve nela e excede ao mesmo tempo a injustiça do chamado "capitalismo". Se não cito textualmente em meu texto as palavras de Derrida, é por desejar marcar uma distância em relação a um discurso fascinante, mas de cujo fascínio minha leitura quer "desconfiar”. Retirando crédito a esse texto que a fundamenta, sem deixar de reconhecer a dívida, o que resta para garantir minha leitura? A questão é fundamental e complexa - ela passa, talvez, por uma moratória intelectual, ou uma "paixão ingrata”, título de um texto de Marcos Siscar no livro Em torno de Jacques Derrida (Rio de Janeiro, 7 Letras, 2000).
" (Genet, Jean. Journal du voleur. Op. cit.: 9)

*(: 122)

"(Genet, Jean. O Ateliê de Giacometti. Op. cit.: 38) 
* (Cf. Jacques Derrida, Spectres de Marx. Paris: Galilée, 1993. Valem as considerações que faço na nota 3)

" (Genet, Jean. Journal du voleur. Op. cit.: 50) uma troca. Não há cálculo no limite, no horizonte teórico da questão. Esse dom seria capaz de provocar um curto-circuito na organização da sociedade como a conhecemos.

A pergunta persiste: num outro contexto, mais implicado na discussão da organização social do que nos mecanismos de estetização, não haveria alienação, exploração, expropriação, devoração do outro que serve de material para o exercício da transfiguração? Muito embora a obra estetizante faça muito pelo estatuto do ser que representa, conferindo-lhe uma dignidade, transfigurando-a, justamente. Fazendo justiça, ao menos discursivamente. Ou apenas discursivamente. Mas a justiça, o que seria, além de um ponto não saturado, indefinidamente em aberto, no discurso?**

É a escultura de Giacometti, principalmente, que atrai a atenção de Genet. Tem caráter hierático, arcaico, está em relação com a tumba, o túmulo, a divindade, é uma obra que lhe parece "feita para os mortos”. Tal associação implica uma concepção de justiça que seria aplicável apenas em relação aos mortos, por uma espécie de dívida ou de atração irresistível? Ou fazendo uma obra para os mortos, esses solitários que já não dispõem de disfarce para sua solidão, cuja vestimenta se desfaz deixando aparecer a nudez última dos ossos, se estaria sublinhando o infindável, a necessidade de recomeçar sempre a tarefa de glorificar a solidão de cada um? Barroco, Genet mantém a morte sempre ao alcance da mão.

Se buscarmos na obra de Genet, ainda nesse texto impressionante que é Diário de um ladrão, a traição é a face sombria do sentimento democrático de solidão de todos. Elas se relacionam estreitamente e estão na base da paradoxal busca estética de Genet:

É talvez sua solidão moral - à qual aspiro - que me faz admirar os traidores e amá-los*.

Às vezes a consciência com que teremos pensado um ato vil, a potência de expressão que deve significá-lo, nos forçam ao canto. É que ela é bela se a traição nos faz cantar*.

Se todos somos sós, trair uns aos outros pode equivaler a não trair a solidão, a gloriosa e inigualável solidão de cada ser, não cedendo a princípios gregários que buscariam anular essa solidão através das redes sociais, das redes de valores morais. $\mathrm{Na}$ vida de Genet e na nossa, é possível saber como se trai. Talvez sejamos especialistas nisso sem termos consciência clara 
a esse respeito. Mas como a arte pode trair os objetos que estetiza? Explorando-os? Talvez. Talvez transfigurando o próprio artista, fazendo dele um personagem, alguém famoso, recaindo assim na mediocridade e na violência que a obra buscava talvez desativar?** Talvez.

\section{Conclusão}

Genet, que foi ao mesmo tempo artista e assumidamente personagem (talvez já desejando ser artista, como podemos imaginar por seu autobiográfico Diário de um ladrão), provavelmente trai essa traição em seu próprio caso, mantendo com a fama, como reza a lenda, relações marcadas por uma forte dose de estranhamento. Nesse sentido, Sartre comenta sobre o "sucesso" do antigo condenado: "Aceito, mimado, Genet permanece em exílio no seio de seu triunfo. Tanto melhor: esse novo fracasso e a permanência de seu exílio salvaguardam sua grandeza"* Mas no Diário, comparando-se com sua miséria narrada, no momento da narrativa em que irrompe na narração (enfim, pelo menos em algum de seus níveis justapostos), Genet apresenta uma situação mais complexa do que a afirmada por Sartre:

Escrevo este livro num palácio de uma das vilas mais luxuosas do mundo onde sou rico, ao passo que não posso lamentar os pobres: eu os sou. Se é doce para mim desfilar diante deles, deploro, muito precisamente, não poder fazê-lo com mais fausto e insolência."

Apesar dessa consciência da complexidade de suas relações com a miséria da qual emerge e com sua própria condição de autor, de certo modo, Genet talvez acabe traindo Giacometti, transfigurando-o, fazendo dele uma "personalidade" no texto que escreve sobre sua arte, influenciado nisso possivelmente pela interpretação existencialista - Sartre o teria colocado em contato com Giacometti, Sartre escreve sobre "as pinturas de Giacometti”, chamando-o de “prestidigitador”, mestre das aparições e desaparecimentos, hábil ilusionista interrogando com seus truques o próprio ser*.

Curiosamente, para seu próprio caso, Genet está consciente do perigo que corre, e é taxativo quanto à importância de manter uma "soberania” - pelo menos enquanto narrador do Diário, livro que é aliás dedicado a Sartre e a Simone de Beauvoir. Assim, ele diz:

A boa vontade dos moralistas se quebra contra o que eles chamam minha má fé. Se eles podem me provar que um ato é detestável pelo mal que ele faz, só eu posso decidir, pelo canto que levanta
" (Cf. O tratamento dado à questão por André R. Rios, em Nada. Isto não é um livro. Rio de Janeiro: Garamond, 2001)

" (Genet, Jean. Journal du voleur. Op. cit.: 100)

" (Sartre, Jean-Paul. "Les peintures de Giacometti". Situations IV. Paris: Galli. mard, 1964) martyr". Oeuvres complètes Gallimard, 1952: 644) 
em mim, sobre sua beleza, sobre sua elegância; só eu posso recusálo ou aceitá-lo. Não serei reconduzido ao bom caminho. No máximo poderiam empreender minha reeducação artística - com o risco, entretanto, para o educador, de deixar-se convencer e ganhar para a minha causa se a beleza se prova por, de duas personalidades, a soberana.*

Genet se sabe objeto da leitura existencialista de Sartre, que ele aceita e recusa, e nesse processo pode identificar-se com Giacometti e assumir o lugar do crítico. Assim, ocupa alternadamente a posição de objeto e de sujeito da crítica para compor sua leitura da inquietante arte de Giacometti, em que ele vê o triunfo da transfiguração e a glorificação da solidão. 


\section{Paula Glenadel}

Professora de Língua e Literatura Francesa na UFF (Niterói, RJ). Doutora em Letras Neolatinas pela UFRJ. Realizou estágio de pósdoutorado sobre poesia francesa na Université de Paris VIII. Publicações recentes: "Vozes de Baudelaire na poesia francesa", Revista Cult, n. 73, outubro de 2003; "Do pé à dança: Chaussure de Nathalie Quintane”. Publicação do Seminário Vozesfemininas da Fundação Casa de Rui Barbosa, Rio de Janeiro, 2003; "Derrida e os poetas: de margens e marcas”. Em: Nascimento, Evando e Glenadel, Paula (org.) Em torno de Jacques Derrida. Rio de Janeiro: 7 Letras, 2000.

\section{Resumo}

O trabalho interroga a interpretação dada por Genet da arte de Giacometti, em função da capacidade de estetização do mundo que o primeiro atribui ao segundo. Transfigurando a nudez, a solidão, em condição "gloriosa”, o pintor-escultor consegue evidenciar a singularidade de cada ser e de cada objeto. Faz parte dos horizontes do trabalho ver como essa transfiguração pode atingir a própria imagem do artista, tornado personagem para o crítico.

\section{Abstract}

This paper interrogates the interpretation given by Genet of Giacometti's art, based on the capacity of aesthetisation of the world the critic sees in it. By transfiguring nakedness and loneliness in "glorious" condition, the painter-sculptor points out the singularity of each being and each object. One must also consider how this transfiguration can touch the artist's image itself, once he is considered as character by the critic.

\section{Résumé}

Le travail interroge l'interprétation faite par Genet de l'art de Giacometti, en fonction de la capacité d'esthétisation du monde qu'il lui attribue. Transfigurant la nudité, la solitude, en condition "glorieuse", le peintresculpteur met en évidence la singularité de chaque être et de chaque objet. Il faut aussi considérer comment cette transfiguration peut atteindre l'image même de l'artiste, devenu personnage pour le critique.

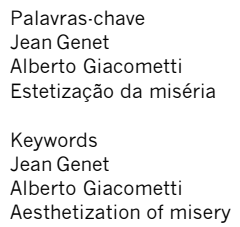

Recebido em 28/12/2002 Aprovado em 12/07/2003 